\title{
Prevalence of anemia and associated factors among pregnant women in Adigrat General Hospital, Tigrai, northern Ethiopia, 2018
}

\author{
Brhane Berhe*, Fitsum Mardu, Haftom Legese, Aderajew Gebrewahd, Guesh Gebremariam, Kebede Tesfay,
} Getachew Kahsu, Hadush Negash and Gebre Adhanom

\begin{abstract}
Objectives: Anemia remains a major public health problem in Ethiopia, which causes maternal and fetal severe consequences. In Tigrai, there are limited literatures on prevalence of anemia and associated factors among pregnant women. Thus, a hospital based cross-sectional study was conducted to determine the prevalence and associated factors of anemia in Adigrat General Hospital. Data was analyzed and computed using SPSS version 22. $p$ value $=0.05$ at 95\% confidence interval was considered statistically significant.

Results: Overall prevalence of Anemia among the pregnant women attending Adigrat General Hospital was 7.9\%. About $62.5 \%$ and $37.5 \%$ of the anemic women were with mild (Hgb: 10.0-10.9 g/d1) and moderate (Hgb: 7-9.9 g/ dl) type respectively. Factors like, residing in rural areas increases risk of anemia by 6 times (AOR =6, 95\% Cl 1.34, 27.6, $\mathrm{p}=0.019)$, participants having current blood loss ( $\mathrm{AOR}=3.4,95 \% \mathrm{Cl} 1.16,10.2, \mathrm{p}=0.026)$, having history of recent abortion $(A O R=7.9,95 \% \mathrm{Cl} 2.23,28.1, p=0.001)$ and gestational age in the third trimester $(\mathrm{AOR}=4.9,95 \% \mathrm{Cl} 1.39$, $17.6, p=0.013)$ were statistically associated with anemia. Generally, prevalence of anemia is found to be low in the study area. However, it should be given due attention. Therefore, strong endeavor is needed to control anemia among pregnant women by assessing different micronutrient deficiencies for further prevention.
\end{abstract}

Keywords: Anemia, Ethiopia, Factors, Pregnant women

\section{Introduction}

Anemia is a condition defined with less hemoglobin $(\mathrm{Hgb})$ level than the normal range in the body, which decreases oxygen-carrying capacity of red blood cells to tissues [1]. World Health Organization (WHO) and Center of Disease Control and Prevention (CDC) definitions for anemia differ with age, sex and pregnancy status. The classification is as follows: children 6 months to 5 years anemia is defined as a Hgb level $<11 \mathrm{~g} / \mathrm{dl}$, children $5-11$ years $\mathrm{Hgb}<11.5 \mathrm{~g} / \mathrm{dl}$, adult males $\mathrm{Hgb}<13$ g/dl; non-pregnant women $\mathrm{Hgb}<12$ g/dl and pregnant women $\mathrm{Hgb}<11 \mathrm{~g} / \mathrm{dl}[2,3]$.
*Correspondence: birhaneberhe54@gmail.com

Department of Medical Laboratory Science, College of Medicine

and Health Science, Adigrat University, Adigrat, Ethiopia
Globally, Anemia is one of the public health concerns, which affects 32.4 million (38.2\%) pregnant women around the world. Particularly, common in South East Asia (48.7\%) [4, 5]. Worldwide, it has been reported that nearly 510,000 maternal deaths occur per year associated with childbirth or early post-partum. Approximately $20 \%$ of maternal death is caused by anemia; with majority of deaths occurred in developing countries [6].

Anemia is the main cause of morbidity and mortality among pregnant women in developing countries with maternal and fetal consequences [7], which leads to premature births [8], low birth weight [9], fetal cognitive impairment, and death $[10,11]$.

According to the WHO report of 2008, in Africa, 57.1\% of the pregnant women were anemic [12]. Moreover, anemia among pregnant women is having a severe public health problem in Ethiopia with an overall prevalence of $62.7 \%$. Seventeen percent of Ethiopian women in the 
reproductive age group are anemic and $22 \%$ of them women were pregnant [13-16].

The reason of anemia during pregnancy in developing countries includes nutritional deficiencies of iron, folate, and vitamin B12 and parasitic diseases, such as malaria and hookworm. The relative contribution of each of these factors to anemia varies greatly by geographical location, season, and dietary practices [7]. Despite the efforts made by the government and other stakeholders, anemia during pregnancy is still a public health problem in Ethiopia. Since there is limitation of information in the study area, this study was aimed to determine the prevalence and associated factors of anemia in pregnant women in Adigrat General Hospital.

\section{Main text}

\section{Study design, period and area}

Hospital based cross-sectional study was conducted in Adigrat General Hospital from April-September 2018. The Hospital is found in Adigrat town, located around $905 \mathrm{~km}$ north of Addis Ababa (capital city of Ethiopia) at an latitude and longitude of $14^{\circ} 16^{\prime} \mathrm{N} 39^{\circ} 27^{\prime} \mathrm{E}$, with an ele-

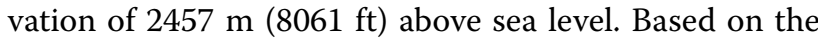
2007 Census conducted by the Central Statistical Agency of Ethiopia (CSA), the town has a total population of 57,588 , people (26,010 are men and 31,578 women). Currently, the Hospital is serving as a teaching hospital, emergency, inpatient and outpatients services for more than 600,000 people who live in eastern zones of Tigrai and Afar regional state. The Hospital has high prevalence of intestinal protozoan parasitic infection.

\section{Study participants}

The study participants were pregnant women greater than 18 years of age and given informed consent who were requested for blood and stool examination in the Hospital during the study period. Convenience sampling technique was employed to enroll the study participants.

\section{Sample size}

A total of 304 participants were determined using single population proportion formula by assuming: 95\% level of confidence, $5 \%$ margin of error and $\mathrm{P}$ (proportion) of 0.235 [3] and non-response rate of $10 \%$.

The degree for severity of anemia in pregnancy was classified into three as per WHO criteria [12]:

- Mild anemia: $10.0-10.9 \mathrm{~g} / \mathrm{dl}$

- Moderate anemia: 7.0-9.9 g/dl

- Severe anemia: $<7.0 \mathrm{~g} / \mathrm{dl}$

\section{Method of data collection}

Questionnaire Data on sociodemographic characteristics of study participants and determinant factors of anemia were collected using interviewer based questionnaire by taught data collectors.

Stool examination Labeled stool cup with leak proof covers possessing respective sequential numbers were offered for the study participants. Faecal specimens were carried out by wet mount.

Wet mount technique Fresh stool samples (about $2 \mathrm{mg}$ of stool) were placed on a slide with wooden applicator, emulsified with a drop of physiological saline $(0.85 \%)$ enclosed with cover slide and examined at $10 \times$ and $40 \times$ microscopic objectives [17].

Blood examination Labeled venous or heparinized blood samples giving sequential numbers of the study participants were used. Blood samples were used for Hemoglobin determination (by using HemoCue). Thin smear was prepared to observe morphology of the red blood cells.

Hemoglobin determination A venous blood sample was taken, filled to micro cuvette, Wipe off excess blood from the outside of the micro cuvette tip, and then placed in the cuvette holder of the device for measuring hemoglobin concentration [17].

Red blood cell morphology Blood sample was taken from the study participants, a drop of blood was placed on new slide, and thin smear was prepared. After being air-dried, labeled with identification number, the smear of the slide was fixed with absolute methanol and the smear was stained with giemsa solution based on the standard operational procedures (SOPs) and examined at $10 \times$ and $100 \times$ microscopic objectives [17].

\section{Quality control}

Questionnaires were pre-tested prior to the actual data collection. The collected data were checked for consistency and completeness daily. All the laboratory procedures were conducted as per the standard operating procedures (SOPs).

\section{Statistical analysis}

Data were entered and analyzed using SPSS version 22 . Then, summarized using descriptive statistics. Bi-variate and multi-variate regression tests were employed to measure the strength of association between dependent and independent variables. Variables with $\mathrm{p}<0.20$ in the 
bi-variate logistic regression were transferred to multivariate regression analysis to compute AOR. $p$-value less than 0.05 was considered statistical significant.

\section{Ethical consideration}

The study was approved by college of health Sciences Research Ethical review committee of Adigrat University, Ethiopia (consent ref. Number AGU/ CMHS/096/2018APROVAL dated 18/02/2018. Official letter was obtained from Tigrai Regional Health Bureau to Adigrat General Hospital. Permission was also obtained from Administrator of Adigrat general Hospital. Furthermore, after explaining the importance of study, an informed written consent was obtained from study participants. No name was mentioned during the entire data collection and identification was based on the unique identification number given for each questionnaire and corresponding specimen. Confidentiality of information (results) was kept between the study participant, data collector/investigator and authorized physician. Those study participants who were anemic and showed intestinal parasites were reported to physician to treat according to the national protocol.

\section{Results}

\section{Socio-demographic characteristics}

A total of 304 pregnant women were included in the study. The mean age of the study participants was $25.3 \pm 5.1$ (ranged from 18 to 41 years). Out of 304 participants, 217 (71.4\%) were living in urban areas and the rest 87 (28.6\%) were rural dwellers. More than Half, 235 (77.3\%), of the study participants were housewife followed by self-employee, $39(12.8 \%)$ and governmental employee, 30 (9.9\%) (Table 1).

\section{Laboratory findings}

Among 304 study participants, 24 (7.9\%) were anemic $(\mathrm{Hgb}:<11 \mathrm{~g} / \mathrm{dl})$. The general distribution of anemia was 15 (62.5\%) microcytic hypochromic, 6 (25.0\%) normocytic hypochromic and 3 (12.5\%) macrocytic hypochromic based on the morphology of red blood cells. Entamoeba histolytica 24 (7.9\%), Giardia lamblia and both Entamoeba histolytica/dispar and Giardia lamblia 15 (4.9\%) were among intestinal parasites detected from stool of the pregnant women (Table 2). The majority of anemic cases $62.5 \%(15 / 24)$ showed mild type of anemia (Fig. 1).

\section{Factors associated with anemia}

All variables with $\mathrm{p}$ value $<0.2(20 \%)$ in the bivariate analysis were enter and analyzed by multivariate logistic regression. Study participants those who were residing in rural areas $(\mathrm{AOR}=6.0,95 \mathrm{CI} 1.34,27.6, \mathrm{p}=0.019)$, women participants responded having current blood loss $(\mathrm{AOR}=3.4,95 \mathrm{CI} 1.16,10.2, \mathrm{p}=0.026)$, history of recent abortion $(\mathrm{AOR}=7.9,95 \mathrm{CI} 2.23,28.1, \mathrm{p}=0.001)$ and women in third trimester gestational age $(\mathrm{AOR}=4.9$, 95 CI 1.39, 17.6, $\mathrm{p}=0.013$ ) were factors found statistical significant association with anemia. Though, not statistically significant, prevalence of anemia was higher among those who didn't use iron supplement, women who gave birth after a year, among illiterate and housewife (Table 1).

\section{Discussion}

The prevalence of anemia in the present study was $7.9 \%$. This was in line with previous studies conducted in Debre Berhan, 9.7\% [18], Sudan, 10\% [19], Addis Ababa, $11.6 \%$ [20] and Iran, 13.6\% [21]. However, our finding was observed to be lower than other similar studies [1, 22-27] and in South-East Ethiopia, 27.9\% [28]. The difference might be due to geographical variation, differences in socioeconomic status, dietary habits of the study participants [20] and pregnant women with iron supplementation were not excluded in this study. Additionally, the lower occurrence of anemia in this study might be attributed by decreased prevalence of hemoparasites like Malaria in the study area.

In this study, the majority of anemic cases, $62.5 \%$ (15/24) were mild type followed by $37.5 \%$ (9/24) moderate cases of anemia. A similar provision was reported in Kenya (62.5\% and 37.5\%) [24] and Nepal (67.1\%, and $28.6 \%$ ) [29] in which majority of the cases was mild anemia followed by moderate anemia respectively. In contrast to this report, study performed in Kenya $(70.7 \%$ and 26.3\%) [30] and southern Ethiopia (60\% and 34.3\%) [31] majority of the anemia case was moderate followed by mild correspondingly.

History of blood loss (AOR $=3.4,95$ CI 1.16, 10.2, $\mathrm{p}=0.026)$ was significantly associated with the occurrence of anemia. This study was consistent with studies conducted in different parts Ethiopia [31-33]. Similar to a report from South western Ethiopia, history of abortion (AOR =7.9, 95 CI 2.23, 28.1, $\mathrm{p}=0.001)$ was significantly associated with anemia [33]. This might be due to increased loss of blood which depletes stored iron that leads extra requirement of iron than the usual [34].

Moreover, elevated anemia was found with rural residence and third trimester of gestational age. The pregnant women of rural residence were about 6 times high likely to be anemic than the urban dwellers. The risk of getting anemia was also 4.9 times higher among women in the third trimester of gestational age. This study was parallel with the report in Pakistan [35], India [36], Libya [37], Nepal [38], eastern Ethiopia [39] and northwest Ethiopia [40]. In contrast to this study; as reported in 
Table 1 Socio-demographic characteristics of participants and outcome of different factors on the prevalence of anemia in pregnant women attending Adigrat General Hospital, northern Ethiopia, from April to September 2018

\begin{tabular}{|c|c|c|c|c|c|c|}
\hline Variables & Frequency $\mathrm{N}(\%)$ & $\begin{array}{l}\text { Anemia prevalence } \\
\text { Positive (\%) }\end{array}$ & COR $(95 \% \mathrm{Cl})$ & p-value & AOR $(95 \% \mathrm{Cl})$ & $p$-value \\
\hline \multicolumn{7}{|l|}{ Age (in years) } \\
\hline $18-25$ & $169(55.6)$ & 5.32 & 1 & & & \\
\hline $26-34$ & $117(38.5)$ & 10.26 & $0.40(0.2,1.2)$ & 0.100 & & \\
\hline$>34$ & $18(5.9)$ & 16.67 & $0.28(0.06,1.1)$ & 0.070 & & \\
\hline \multicolumn{7}{|l|}{ Educational level } \\
\hline Illiterate & $32(13.8)$ & 43.75 & $0.87(0.7,2.3)$ & 0.700 & & \\
\hline $1-8$ & 87 (28.6) & 3.45 & $0.50(0.9,3.5)$ & 0.350 & & \\
\hline $9-12$ & $160(52.6)$ & 2.50 & $0.40(0.061,5.03)$ & 0.900 & & \\
\hline$>12$ & $15(4.9)$ & - & 1 & & & \\
\hline \multicolumn{7}{|l|}{ Residence } \\
\hline Urban & $213(70.1)$ & 3.75 & 1 & & 1 & \\
\hline Rural & $91(29.9)$ & 17.58 & $8.70(2.01,38.4)$ & 0.004 & $6.00(1.34,27.6)$ & 0.019 \\
\hline \multicolumn{7}{|l|}{ Occupation } \\
\hline Housewife & $235(77.3)$ & 7.65 & $0.39(0.051,3.04)$ & 0.370 & & \\
\hline Self employed & $39(12.8)$ & 7.69 & $1.30(0.08,21.8)$ & 0.850 & & \\
\hline Governmental & $30(9.9)$ & 10.00 & 1 & & & \\
\hline \multicolumn{7}{|c|}{ Pregnancy gap (last and current pregnancy) } \\
\hline 1 year & $37(12.2)$ & 32.43 & $0.02(0.005,0.08)$ & 0.000 & $0.19(0.02,1.70)$ & 0.138 \\
\hline 2 years & $42(13.8)$ & 7.14 & $1.13(0.12,11.3)$ & 0.900 & & \\
\hline 3 years & $42(13.8)$ & 7.14 & $0.50(0.09,3.5)$ & 0.500 & & \\
\hline$>3$ years & $72(23.7)$ & 4.17 & $1.90(0.19,18)$ & 0.600 & & \\
\hline First pregnancy & $111(36.5)$ & 2.70 & 1 & & 1 & \\
\hline \multicolumn{7}{|l|}{ Iron supplements } \\
\hline Yes & $190(62.5)$ & - & 1 & & 1 & \\
\hline No & $114(37.5)$ & 7.90 & $0.08(0.02,0.31)$ & 0.000 & $0.06(0.01,1.22)$ & 0.089 \\
\hline \multicolumn{7}{|c|}{ Presence of current blood loss } \\
\hline Yes & $43(14.1)$ & 41.86 & $5.90(2.17,16.2)$ & 0.001 & $3.40(1.16,10.2)$ & 0.026 \\
\hline No & $261(85.9)$ & 2.29 & 1 & & 1 & \\
\hline \multicolumn{7}{|l|}{ Trimester (weeks) } \\
\hline 1 & $60(19.7)$ & - & 1 & & 1 & \\
\hline 2 & $96(31.6)$ & 3.12 & $2.00(0.79,12)$ & 0.005 & $0.14(0.65,9.12)$ & 0.070 \\
\hline 3 & $148(48.7)$ & 14.18 & $5.00(1.49,17.67)$ & 0.010 & $4.90(1.39,17.6)$ & 0.013 \\
\hline \multicolumn{7}{|c|}{ Recent history of abortion } \\
\hline Yes & $88(29)$ & 17.04 & $9.60(2.76,33.2)$ & 0.000 & $7.90(2.23,28.1)$ & 0.001 \\
\hline No & $216(71)$ & 4.17 & 1 & & 1 & \\
\hline \multicolumn{7}{|c|}{ Current history of malaria } \\
\hline Yes & $42(13.8)$ & 14.28 & $0.04(0.01,0.1)$ & 0.000 & $0.08(0.02,1.26)$ & 0.061 \\
\hline No & $262(86.2)$ & 6.87 & 1 & & & \\
\hline \multicolumn{7}{|c|}{$\begin{array}{l}\text { History of coffee (the } \\
\text { last } 3 \text { months) }\end{array}$} \\
\hline Yes & $212(69.7)$ & 8.01 & $0.12(0.014,0.81)$ & 0.030 & $0.09(0.010,1.84)$ & 0.054 \\
\hline No & $92(30.3)$ & 7.61 & 1 & & & \\
\hline \multicolumn{7}{|c|}{ Home delivery (previous pregnancy delivery) } \\
\hline Yes & $43(14.1)$ & 6.97 & $0.05(0.02,0.13)$ & 0.000 & $0.26(0.04,1.60)$ & 0.145 \\
\hline No & $261(85.9)$ & 8.01 & 1 & & & \\
\hline
\end{tabular}

$\mathrm{COR}$, crude odds ratio, $\mathrm{Cl}$, confidence interval, $\mathrm{AOR}$, adjusted odds ratio); 1 (referent); - (no) 
Table 2 Laboratory finding of the pregnant women attending Adigrat General Hospital, northern Ethiopia, April-September 2018

\begin{tabular}{lc}
\hline Hematocrit value (Hgb value) & Number of cases (\%) \\
\hline Anemic $<33 \%(<11 \mathrm{gm} / \mathrm{dl})$ & $24(7.9)$ \\
Not-anemic $>33 \%(>11 \mathrm{gm} / \mathrm{dl})$ & $280(92.1)$ \\
Red blood examination & \\
Microcytic-hypochromic & $15(62.5)$ \\
Normocytic-hypocromic & $6(25)$ \\
Macrocytic-hypocromic & $3(12.5)$ \\
Stool examination & \\
Entamoeba histolytica/dispar & $24(7.9)$ \\
Giardia lamblia & $15(4.9)$ \\
Entamoeba histolytica/dispar and Giardia & $15(4.9)$ \\
$\quad$ lamblia & $250(82.2)$ \\
No ova or parasite &
\end{tabular}

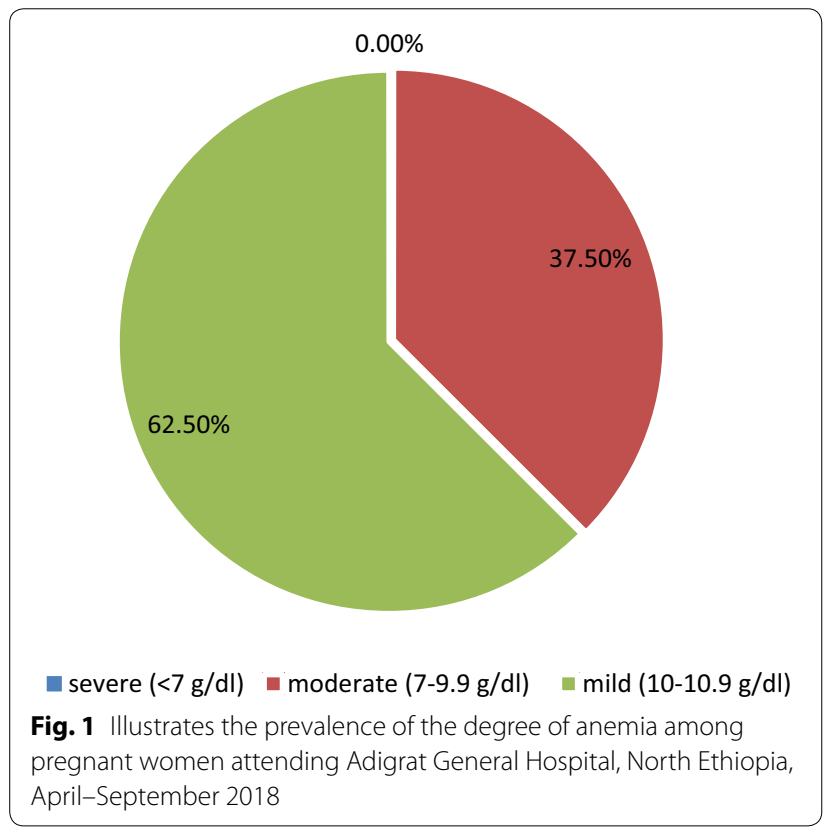

western Nepal [29] and Nigeria [41], the distribution of anemia was higher in second trimester of gestational age.

\section{Conclusions}

This study revealed that the prevalence of anemia among pregnant women was relatively low compared to the findings of other reports in Ethiopia. Rural residence, history of abortion, current blood loss and third trimester gestational age were statistical significant associated factors with anemia in this study. Therefore, further large scale longitudinal studies should be done in respect to the importance of regular visit to maternal care centers and health education promotion programs regarding the cause and prevention of anemia among pregnant women by assessing micronutrients and other causal related factors for anemia.

\section{Limitation of the study}

The study was institutional based study. Further study should be conducted based on community level to make this finding stronger. Besides, the study was restricted cross-sectional study design and didn't address every nutritional variable.

\section{Abbreviations \\ ANC: antenatal care; CDC: Center of Disease Control and Prevention; CSA: Central Statistical Agency; Hgb: hemoglobin; SPSS: statistical product and service solution; SOPs: standard operating procedures; WHO: World Health Organization.}

\section{Acknowledgements}

We are thankful to laboratory personnel, clinicians of Adigrat General Hospital and study participants for their willingness of participation.

\section{Authors' contributions}

BB designed the study, analyzed data and drafted manuscript; FM, HL and GK participated in the design of the study, data analysis and revision of the manuscript; AG participated in the design of the study, data analysis and revision of the manuscript, GG, KT, HN and GA designed the study, analyzed data and wrote and revised the manuscript. All authors read and approved the final manuscript.

\section{Funding}

Not applicable.

\section{Availability of data and materials}

The data sets used and/or analyzed during the current study are available from the corresponding author on reasonable request.

\section{Ethics approval and consent to participate}

Ethical approval was sought from Adigrat University, College of Health Sciences institutional review board (IRB). Written consents were collected from the study participants. Participants' positive for anemia and intestinal parasites were reported to physician to treat according to the national protocol.

\section{Consent for publication}

Not applicable.

\section{Competing interests}

The authors declare that they have no competing interests.

Received: 5 February 2019 Accepted: 29 May 2019

Published online: 31 May 2019
References

1. Alem M, Enawgaw B, Gelaw A, Kena T, Seid M, Olkeba Y. Prevalence of anemia and associated risk factors among pregnant women attending antenatal care in Azezo Health Center Gondar town, Northwest Ethiopia. J Interdiscipl Histopathol. 2013;1(3):137-44.

2. Iron Deficiency Anemia. Assessment prevention and control. Geneva: WHO; 2001

3. Zekarias B, Meleko A, Hayder A, Nigatu A, Yetagessu T. Prevalence of anemia and its associated factors among pregnant women attending antenatal care (ANC) In Mizan-Tepi University Teaching Hospital, South West Ethiopia. Health Sci J. 2017;11(5):529. 
4. WHO. The global prevalence of anemia in 2011.

5. Tadesse SE, Seid O, Gariam Y, Fekadu A, Wasihun Y, Endris K, et al. Determinants of anemia among pregnant mothers attending antenatal care in Dessie town health facilities, northern central Ethiopia, unmatched case-control study. PLoS ONE. 2017;12(3):0173173.

6. Crawley J. Reducing the burden of anemia in infants and young children in malaria endemic countries of Africa: from evidence to action. Am J Trop Med Hyg. 2004;71:25-34.

7. Getahun W, Belachew T, Wolide AD. Burden and associated factors of anemia among pregnant women attending antenatal care in southern Ethiopia: cross sectional study. BMC Res Notes. 2017;10:276.

8. Levy A, Fraser D, Katz M, Mazor M, Sheiner E. Maternal anemia during pregnancy is an independent risk factor for low birth weight and preterm delivery. Eur J Obstetrics Gynecol Reprod Biol. 2005;122(2):182-6.

9. Banhidy F, Acs N, Puho EH, Czeizel AE. Iron deficiency anemia: pregnancy outcomes with or without iron supplementation. Nutrition. 2011;27(1):65-72.

10. Kalaivani K. Prevalence \& consequences of anemia in pregnancy. Indian J Med Res. 2009;130(5):627-33.

11. Walter T. Effect of iron-deficiency anemia on cognitive skills and neuromaturation in infancy and childhood. Food Nutr Bull. 2003;24(4):104-10.

12. Benoist B, McLean E, Egli I, Cogswell M. World Health Organization, centers for disease control and prevention: worldwide prevalence of anemia 1993-2005. Geneva: World Health Organization; 2008.

13. Gebre A, Mulugeta A. Prevalence of anemia and associated factors among pregnant women in North Western zone of Tigray, Northern Ethiopia: a cross-sectional study. J Nutr. 2015;2015:165430.

14. Ethiopia Demographic, Survey Health. Central statistics agency. Ethiopia: Addis Ababa; 2011.

15. Ayano B, Amentie B. Assessment of prevalence and risk factors for anemia among pregnant mothers attending ANC Clinic at Adama Hospital Medical Collage, Adama, Ethiopia. J Gynecol Reprod. 2018;6(3):31-9.

16. WHO. Hemoglobin concentrations for the diagnosis of anemia and assessment of severity, vitamin and mineral nutrition information system. Geneva: WHO; 2011

17. Cheesbrough M. District laboratory practice in tropical countries 2009, part 1. 2nd ed. Cambridge: Cambridge University Press; 2009.

18. Abere Y. Pregnancy anemia prevalence and associated factors among women attending ante natal care in North Shoa Zone, Ethiopia. RSSDIJ. 2014;3:3.

19. Abdelgader EA, Diab TA, Kordofani AA, Abdalla SA. Hemoglobin level, RBCs Indices, and iron status in pregnant females in Sudan. Basic Res J Med Clin Sci. 2014;3(2):8-13.

20. Gebreweld A, Tsegay A. Prevalence and factors associated with anemia among pregnant women attending antenatal clinic at St. Paul's Hospital Millennium Medical College, Addis Ababa, Ethiopia. Adv Hematol. 2018;2018:3942301.

21. Barooti M, Rezazadehkermani B, Sadeghirad S, Motaghipisheh S, Arabi M. Prevalence of iron deficiency anemia among Iranian pregnant women; a systematic review and meta-analysis. J Reprod Fertil. 2010;11(1):17-24.

22. Kumari S, Priya J. Prevalence of anemia risk factors in pregnant women. IJSR. 2016;5:4

23. Lelissa D, Yilma M, Shewalem W, Abraha A, Worku M, Ambachew H, et al. Prevalence of anemia among women receiving antenatal care at Boditii Health Center, Southern Ethiopia. J Clin Med Res. 2015:4(3):79-86.

24. Siteti M, Namasaka SD, Ariya OP, Injete SD, Wanyonyi WA. Anaemia in pregnancy: prevalence and possible risk factors in Kakamega County, Kenya. SJPH. 2014;2(3):216-22.
25. Acheampong K, Appiah S, Awuah DB, Arhin YS. Prevalence of anemia among pregnant women attending antenatal clinic of a selected Hospital in Accra, Ghana. IJHSR. 2018:8:1.

26. Haniff J, Das A, Teck I, Sun CW, Mrcog NM, Rampal S, et al. Anemia in pregnancy in Malaysia: a cross-sectional survey. Asia Pac J Clin Nutr. 2007;16(3):527-36.

27. Zhanga Q, Lic Z, Ananth CV. Prevalence and risk factors for anaemia in pregnant women: a population-based prospective cohort study in China. Paediatr Perinat Epidemiol. 2009:23:282-91.

28. Kefiyalew F, Zemene E, Asres Y, Gedefaw L. Anemia among pregnant women in Southeast Ethiopia: prevalence, severity and associated risk factors. BMC Res Notes. 2014;7(1):1.

29. Singh P, Khan S, Mittal RK. Anemia during pregnancy in the women of western Nepal. BMJ. 2013:2(1):14-6.

30. Tekeste $O$. Prevalence and factors associated with anaemia among pregnant women attending antenatal clinic in the second and third trimesters at Pumwani maternity Hospital, Nairobi, 2015 (un-published).

31. Gedefaw L, Ayele A, Asres Y, Mossie A. Anemia and associated factors among pregnant women attending antenatal care clinic in Wolayita Sodo Town, southern Ethiopia. Ethiop J Health Sci. 2015:25:2.

32. Jufar AH, Zewde T. Prevalence of anemia among pregnant women attending antenatal care at Tikur Anbessa Specialized Hospital, Addis Ababa Ethiopia. J Hematol Thromb Dis. 2014;2:125.

33. Zekarias B, Meleko A, Hayder A, Nigatu A, Yetagessu T. Prevalence of anemia and its associated factors among pregnant women attending antenatal care in Mizan-Tepi University Teaching Hospital, South West Ethiopia. Health Sci J. 2017:11(5):529.

34. Tadesse SE, Seid O, Mariam YG, Fekadu A, Wasihun Y. Determinants of anemia among pregnant mothers attending antenatal care in Dessie town health facilities, northern central Ethiopia, unmatched case-control study. PLOS ONE. 2017:12:e0173173.

35. Ullah I, Zahid M, Khan MI, Shah M. Prevalence of anemia in pregnant women in district Karak, Khyber Pakhtunkhwa, Pakistan. IJB. 2013;3(11):1-7.

36. Suryanarayana R, Santhuram AN, Chandrappa M, Shivajirao P, Rangappa SS. Prevalence of anemia among pregnant women in rural population of Kolar district. Int J Med Sci Public Health. 2016;5:3.

37. Elzahaf R, Omar M. Prevalence of anaemia among pregnant women in Derna city, Libya. Int J Community Med Public Health. 2016;3(7):1915-20.

38. Rayamajhi N, Mishra SK, Gautam N, Doshi NR. Prevalence of anemia in pregnant women attending a tertiary level hospital in western region, Nepal. JUCMS. 2016:4(2):14

39. Bereka SG, Gudeta AN, Reta MA, Ayana LA. Prevalence and associated risk factors of anemia among pregnant women in rural part of JigJiga City, Eastern Ethiopia: a cross sectional study. J Preg Child Health. 2017;4:337

40. Asri F. Prevalence of anemia and its associated factors among pregnant women receiving antenatal care at Aymiba Health Center, northwest Ethiopia. J Blood Med. 2017;8:35-40.

41. Dattijo LM, Daru PH, Umar NI. Anaemia in pregnancy: prevalence and associated factors in Azare, North-East Nigeria. IJTD. 2016;11(1):1-9.

\section{Publisher's Note}

Springer Nature remains neutral with regard to jurisdictional claims in published maps and institutional affiliations. 